\title{
Study of superoxiddismutase activity dynamics in rat skeletal muscle tissue under mechanical influence on hemato-ophthalmic barrier
}

\author{
Anatoly Devyatkin ${ }^{1}$, Olga Pavlova ${ }^{2,3,}$, Olga Gulenko ${ }^{2}$, Pavel Boriskin ${ }^{1}$, and Olga Tulaeva ${ }^{4}$ \\ ${ }^{1}$ Kazan State Academy of Veterinary Medicine named after N.E. Bauman, 420074, st. Siberian tract, \\ 35, Kazan, Republic of Tatarstan, Russia \\ ${ }^{2}$ Samara State University of Railways, 443077, Svobody st., 2B, Samara, Russia \\ ${ }^{3}$ Private institution educational organization of higher education "Medical University "Reaviz", \\ 443099, st. Chapaevskaya, 227, Samara, Russia \\ ${ }^{4}$ Samara State Medical University" of the Ministry of Health of the Russian Federation, 443099, st. \\ Chapaevskaya, 89, Samara, Russia
}

\begin{abstract}
Hemato-ophthalmic barrier is one of the mechanisms of body resistance. One of the complications of mechanical trauma of the eye and violation of the hemato-ophthalmic barrier is the emergence of oxidative stress on the background of the general inflammatory process. Normally, oxidative stress in the skeletal muscle tissue is not a damaging agent, but when intensified by other factors, it promotes pathological changes in the body. Objective: to study the dynamics of superoxiddismutase (SOD) activity in rat skeletal muscle tissue under oxidative stress caused by mechanical action on the hemato-ophthalmic barrier. Materials and methods: The study was carried out on pedigree matured male rats in the amount of 150 pieces. The activity of SOD in skeletal muscle tissue was studied before the experiment, as well as on the 1st, 3rd, 5th, 7th and 14th day of the experiment using the standard technique of V.S. Gurevich. The obtained digital material was subjected to statistical processing by means of non-parametric statistical analysis. Conclusion: SOD activity in rat skeletal muscle tissue under oxidative stress caused by mechanical action on hemato-ophthalmic barrier is most effectively stabilized in standard therapy of mechanical eye injury with the addition of quercetin in the form of injections.
\end{abstract}

\section{Introduction}

Hemato-ophthalmic barrier is one of the mechanisms of resistance, which serves to protect the body and prevents homeostasis disorder when the body is affected by factors that can disturb this balance. It regulates the entry into and removal from the eye of various substances typical of normal and pathological metabolism, and it also performs an immune function, preventing the penetration of microorganisms, antibodies and leukocytes [1]. One of the complications of mechanical trauma of the eye and violation of hemato-ophthalmic

\footnotetext{
*Corresponding author: casiopeya13@mail.ru
} 
barrier is the appearance of oxidative stress on the background of the general inflammatory process in case of cellular structures disorders. Oxidative stress is a failure of the body's antioxidant system, in which cells are exposed to excessive concentrations of reactive oxygen forms and other free radicals [2]. Normally, any reaction of an organism under the action of stress factors (mechanical trauma of the eye) can be accompanied by a short-term increase in the number of reactive oxygen forms [3, 4].

It was found that skeletal muscles have the ability to significantly increase oxygen consumption during contraction [5]. It also leads to the intensification of free-radical oxidation, initiation of adaptation and reparation processes or, under certain conditions, to the development of disadaptosis and functional deficit. Skeletal muscles have several sources of production of reactive oxygen forms both at rest (mitochondrial respiratory chain [6], phospholipase A2 [7], arachidonic acid metabolism lipoxygenase pathway) and in the processes of muscle contraction - $\mathrm{HAD}(\mathrm{F}) \mathrm{H}$-oxidase [8], xanthine-oxidase [9], etc., as well as in the process of muscle contraction. Muscle contraction in general leads to the formation of free-radical products with a speed determined by the specificity, intensity, frequency and duration of physical activity [10].

Normally, oxidative stress in skeletal muscle tissue is not a pronounced damaging factor, it initiates an adequate intensity and volume of physical activity, the excitation of adrenergic regulation with corresponding energy expenditure and the development of physiological hypoxia, but when oxidative stress is intensified by other factors (for example, due to mechanical trauma of the eye), it promotes pathological changes in the body, particularly in skeletal muscle tissue [11]. Hypoxic state associated with increased breathing intensity at the moment of transition to physical activity in tissue cells is one of the factors in formation of activated mitochondrion state [12]. Hypoxia initiates the formation of reactive oxygen forms with subsequent deployment of free-radical and peroxide reactions through moderate mobilization of endogenous fatty acids and stimulation of sympathoadrenal system [13]. The accumulation of endogenous oxygen in the process of free-radical reactions provides maintenance of intensive energy exchange and attraction of free-radical oxidation products to metabolic processes [14].

Pathological consequences for the metabolic background in the body arise from the excessive accumulation of active forms of oxygen and their secondary products in case of failure of its own antioxidant system to maintain prooxidant antioxidant balance. The most important biopolymers - nucleic acids, proteins and lipids - are damaged in this case [15]. In the residues of polyunsaturated fatty acids, which are part of cell membranes, reactive oxygen forms cause initiation of chain reactions with the accumulation of lipid radicals, alkoxils, peroxides and hydroperoxides. In the presence of metals with variable valence, the chain oxidation process becomes branched (chain) in character. Stable nonradical freeradical oxidation products are also formed: primary (diene conjugates, hydroperoxides, epoxides), secondary (alkanals, alkenals, malone dialdehyde, trienketones) and final (Schiff bases; pentane, heptane, hexanal and other gaseous products). Under such conditions, the number of free radicals is kept at the same level, and the products of lipid peroxidation in the cell and the extracellular matrix are increased [16].

The basis of action of free-radical oxidation products in the processes of protein inactivation is the interaction with active sulfur-containing, amino-containing and methyl groups of their molecules, which may lead to changes in the tertiary and quaternary protein structure, the formation of protein-protein cross-links and fragmentation of molecules. As a result, the multi-faceted functional activity of proteins (enzymatic, regulatory, participation in matrix syntheses and ion transport) is reduced (or lost), and some of these functional shifts of protein structure contribute to mutations or lead to the formation of autoantigens and disturb the immune balance in the body. It should be noted that although the oxidation 
of proteins has a complex selective character, but due to the influence of reactive oxygen forms common products - carbonyl derivatives - are formed [17].

On the cellular level, the damaging effect of reactive oxygen forms consists mainly in disrupting the organization of membrane structures that determine the phase transitions (gel-liquid crystal) and their functional activity. Changes in lipid-protein bilayer structure under the influence of active oxygen forms affect membrane viscosity, inactivate membrane-bound receptors and enzymes, increase nonspecific permeability for calcium ions, contribute to the release of lysosomal enzymes (protease and nuclease). Further it leads to activation of limited proteolysis and violation of membrane integrity of subcellular organelles, resulting in rough changes in membrane permeability and barrier function for many molecules, reduced ability to bind enzymes [17].

Thus, the purpose of our study was to study the dynamics of superoxiddismutase activity in rat skeletal muscle tissue under oxidative stress caused by mechanical action on the hemato-ophthalmic barrier.

In order to realize the goal it was necessary to solve the following tasks: to determine the changes of superoxiddismutase activity in the skeletal muscle tissue of intact rats and rats with induced oxidative stress caused by mechanical influence on the hematoophthalmic barrier; to determine the effectiveness of oxidative stress relief when applying different methods of eye injury treatment.

\section{Materials and methods}

The study was carried out on white pedigree matured healthy male rats of six months of age, weighing $210-230 \mathrm{~g}$ in the amount of 150 pieces, which were contained in the vivarium under standard conditions.

All animals were divided into 5 groups of thirty rats in each group. Animals of group 1 are intact rats. Animals of the 2, 3, 4 and 5 groups were applied in a special fixation device - a penetrating wound to the right and left eye in the limb area with the help of a microblade under local anesthesia with the use of two percent solution of novocaine. The cornea, sclera and vascular tract were injured. Animals in 2 groups were kept without treatment. Animals of the 3 groups were treated with standard therapy for mechanical eye injury, which included daily injection of subcutaneous dexamethasone phosphate of $0.1 \mathrm{mg} / \mathrm{kg}$ of body weight once a day, sodium diclofenac of $0.5 \mathrm{mg} / \mathrm{kg}$ once a day, gentamicin sulfate of 1.5 $\mathrm{mg} / \mathrm{kg} 2$ times a day. Also dexamethasone 4 times a day and mesaton 2 times a day (in titration according to animal weight) were installed in the damaged eye. This treatment scheme was carried out within a week after the injury. Then during the month continued the installation of dexamethasone solution on a descending scheme $(3,2,1$ time a day for 2 days each mode) and Nevanaka 4 times a day (or broxinaka 1 time a day). Animals of the 4 groups also received standard therapy for eye injury, but were added intraperitoneal injections of flavonoid quercetin (ICN, USA) in a dose of $5 \mathrm{mg} / \mathrm{kg}$ mass. Animals of group 5 received only intraperitoneal injections of quercetin in a dose of $5 \mathrm{mg} / \mathrm{kg}$ mass. The therapy of mechanical eye injury lasted 14 days. During the experiment, all animals were on a standard vivarium diet with free access to water and food. All groups of rats were involved in the experiment simultaneously, which excludes the influence of external temperature, climatic and other factors on the activity of the studied enzyme in control and experimental groups [18].

The activity of SOD in skeletal muscle tissue was studied before the experiment, as well as on the 1st, 3rd, 5th, 7th, and 14th days of the experiment by the Gurevich V.S. method [19]. In accordance with ethical norms, rats were decapitated under ether anesthesia and then extracted skeletal muscle tissue washed with physiological solution and frozen. Then, by means of mechanical skeletal muscle tissue weighing $1 \mathrm{~g}$ with $9 \mathrm{ml}$ tris-buffer $(\mathrm{pH} \mathrm{7,4)}$ 
homogenates were prepared in automatic homogenizer with the speed of $5000 \mathrm{rpm}$ in the vessel with double walls constantly cooled by running water [19].

The study was carried out in accordance with the rules of laboratory practice in the Russian Federation: Order of the Ministry of Health of the USSR No. 755 of 12.08.1977; Order of the Ministry of Health of the Russian Federation No. 267 of 19.06.2003; the Law "On protection of animals from cruelty", Chapter V, Art. 104679-GD of 01.12.1999. The conclusion of the Bioethics Committee of the "Medical University "Reaviz" № 163 of 29 August 2019 was received for the experiment.

The obtained digital material was subjected to statistical processing by means of nonparametric statistical analysis in order to determine the reliability of differences in the studied groups using Valda-Volfovitz, Kolmogorov-Smirnov and Manna-Whitney criteria.

\section{Results of the study}

The dynamics of superoxyddismutase (Me) activity in rat skeletal muscle tissue is shown in Figure 1.

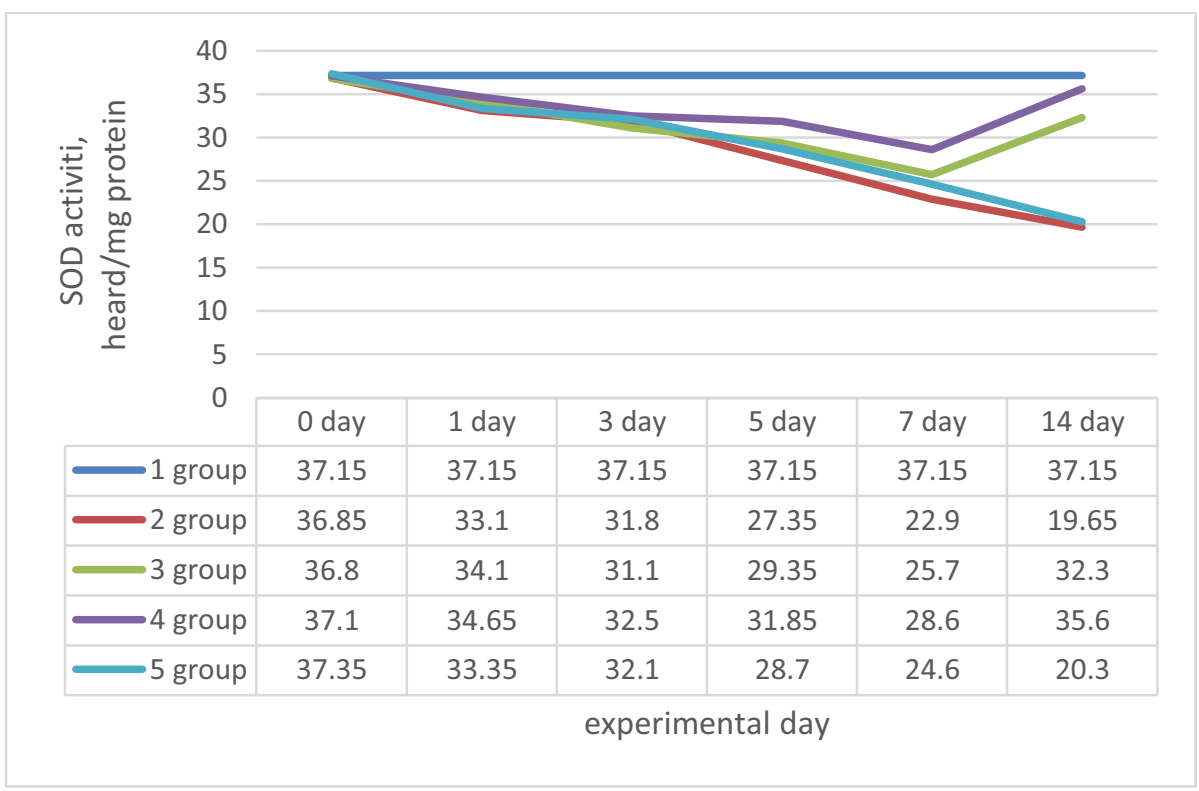

Fig. 1. Dynamics of SOD activity in rat skeletal muscle tissue under oxidative stress caused by mechanical influence on hemato-ophthalmic barrier.

From Figure 1 it follows that intact rats SOD activity throughout the experience was the same and corresponded to the physiological norm. In rats of group 2 with induced oxidative stress throughout the experiment, SOD activity was intensively reduced.

In the animals of the third group with induced oxidative stress by mechanical action on the hemato-ophthalmic barrier and standard therapy of mechanical trauma of the eye there was also a decrease in the activity of superoxiddismutase up to 7 days of the experiment, but by the end of the experiment, by 14 days, the enzyme activity had significantly increased.

In the 4th group of rats with induced oxidative stress and its elimination by standard therapy of mechanical eye injury with addition of quercetin a less intensive decrease of SOD activity was observed up to 7 days of experiment, and by the 14th day the enzyme activity corresponded to physiological norm, though it did not reach the initial value. 
In the fifth group of animals with mechanical trauma of the eye and therapy with exclusively quercetin the decrease of SOD activity is also observed up to the end of the experiment almost as intensively as in animals of the 2 nd group.

The obtained results were processed by non-parametric statistical analysis to determine the reliability of differences in the studied groups using the Valda-Volfowitz, KolmogorovSmirnov and Manna-Whitney criteria (Table 1).

Table 1. Statistical analysis of SOD activity dynamics in rat skeletal muscle tissue against the background of oxidative stress induced by mechanical trauma of the eye.

\begin{tabular}{|c|c|c|c|c|}
\hline Days & Group & Statistical test & Criterion & $\mathbf{p}$ \\
\hline \multirow{24}{*}{ ڤેّ } & \multirow{6}{*}{1 and 2} & \multirow[t]{2}{*}{ Manna-Whitney } & $\mathrm{U}=423,0000$ & \multirow[t]{2}{*}{0,695216} \\
\hline & & & $Z=0,391787$ & \\
\hline & & \multirow[t]{2}{*}{ Kolmogorov-Smirnova } & Max Neg Differnc $=-0,166667$ & \multirow[t]{2}{*}{$>0,10$} \\
\hline & & & Max Pos Differnc $=0,166667$ & \\
\hline & & \multirow[t]{2}{*}{ Walda-Wolfowica } & $\mathrm{Z}=-0,520830$ & 0,602485 \\
\hline & & & $Z$ adjstd $=0,390623$ & 0,696076 \\
\hline & \multirow{6}{*}{1 and 3} & \multirow[t]{2}{*}{ Manna-Whitney } & $\mathrm{U}=362,0000$ & \multirow[t]{2}{*}{0,195792} \\
\hline & & & $\mathrm{Z}=1,293637$ & \\
\hline & & \multirow[t]{2}{*}{ Kolmogorov-Smirnova } & Max Neg Differnc $=-0,066667$ & \multirow[t]{2}{*}{$>0,10$} \\
\hline & & & Max Pos Differnc $=0,233333$ & \\
\hline & & \multirow[t]{2}{*}{ Walda-Wolfowica } & $Z=-0,781246$ & 0,434659 \\
\hline & & & $Z$ adjstd $=0,651038$ & 0,515022 \\
\hline & \multirow{6}{*}{1 and 4} & \multirow[t]{2}{*}{ Manna-Whitney } & $\mathrm{U}=434,5000$ & \multirow[t]{2}{*}{0,824496} \\
\hline & & & $Z=-0,221766$ & \\
\hline & & \multirow[t]{2}{*}{ Kolmogorov-Smirnova } & Max Neg Differnc $=-0,200000$ & \multirow[t]{2}{*}{$>0,10$} \\
\hline & & & Max Pos Differnc $=0,100000$ & \\
\hline & & Walda-Wolfowica & $Z=-0,520830$ & 0,602485 \\
\hline & & & $Z$ adjstd $=0,390623$ & 0,696076 \\
\hline & & Manna-Whitney & $\mathrm{U}=441,5000$ & 0,905850 \\
\hline & & & $\mathrm{Z}=-0,118275$ & \\
\hline & 1 and 5 & Kolmogorov-Smirnova & Max Neg Differnc $=-0,166667$ & $>0,10$ \\
\hline & 1 dild 5 & & Max Pos Differnc $=0,233333$ & \\
\hline & & Walda-Wolfowica & $\mathrm{Z}=-1,82291$ & 0,068318 \\
\hline & & & $\mathrm{Z}$ adjstd $=1,692699$ & 0,090514 \\
\hline & & Manna-Whitney & $\mathrm{U}=0,00$ & 0,000000 \\
\hline & & & $Z=6,645599$ & \\
\hline & 1 and 2 & Kolmogorov-Smirnova & Max Neg Differnc $=0,00$ & $<0,001$ \\
\hline & 1 and 2 & & Max Pos Differnc $=1,000000$ & \\
\hline & & Walda-Wolfowica & $Z=-7,55204$ & 0,000000 \\
\hline & & & $\mathrm{Z}$ adjstd $=7,421834$ & 0,000000 \\
\hline & & Manna-Whitney & $\mathrm{U}=0,00$ & 0,000000 \\
\hline & & & $Z=6,645599$ & \\
\hline & 1 and 3 & Kolmogorov-Smirnova & Max Neg Differnc $=0,00$ & $<0,001$ \\
\hline & 1 and $s$ & & Max Pos Differnc $=1,000000$ & \\
\hline & & Walda-Wolfowica & $Z=-7,55204$ & 0,000000 \\
\hline 㤅 & & & $Z$ adjstd $=7,421834$ & 0,000000 \\
\hline A & & Manna-Whitney & $\mathrm{U}=0,00$ & 0,000000 \\
\hline & & & $Z=6,645599$ & \\
\hline & 1 and 4 & Kolmogorov-Smirnova & Max Neg Differnc $=0,00$ & $<0,001$ \\
\hline & 1 and 4 & & Max Pos Differnc $=1,000000$ & \\
\hline & & Walda-Wolfowica & $Z=-7,55204$ & 0,000000 \\
\hline & & & $Z$ adjstd $=7,421834$ & 0,000000 \\
\hline & & Manna-Whitney & $\mathrm{U}=0,00$ & 0,000000 \\
\hline & & & $Z=6,645599$ & \\
\hline & 1 and 5 & Kolmogorov-Smirnova & Max Neg Differnc $=0,00$ & $<0,001$ \\
\hline & 1 dind 5 & & Max Pos Differnc $=1,000000$ & \\
\hline & & Walda-Wolfowica & $Z=-7,55204$ & 0,000000 \\
\hline & & & $\mathrm{Z}$ adjstd $=7,421834$ & 0,000000 \\
\hline & 1 and 2 & Manna-Whitney & $\mathrm{U}=0,00$ & 0,000000 \\
\hline & & & $Z=6,645599$ & \\
\hline & & Kolmogorov-Smirnova & Max Neg Differnc $=0,00$ & $<0,001$ \\
\hline 桁 & & & Max Pos Differnc $=1,000000$ & \\
\hline$\frac{1}{m}$ & & Walda-Wolfowica & $Z=-7,55204$ & 0,000000 \\
\hline & & & $Z$ adjstd $=7,421834$ & 0,000000 \\
\hline & 1 and 3 & Manna-Whitney & $\mathrm{U}=0,00$ & 0,000000 \\
\hline & & & $Z=6,645599$ & \\
\hline
\end{tabular}




\begin{tabular}{|c|c|c|c|c|}
\hline & & Kolmogorov-Smirnova & Max Neg Differnc $=0,00$ & $<0,001$ \\
\hline & & & Max Pos Differnc $=1,000000$ & \\
\hline & & Walda-Wolfowica & $Z=-7,55204$ & 0,000000 \\
\hline & & & $\mathrm{Z}$ adjstd $=7,421834$ & 0,000000 \\
\hline & 1 and 4 & Manna-Whitney & $\mathrm{U}=0,00$ & 0,000000 \\
\hline & & & $Z=6,645599$ & \\
\hline & & Kolmogorov-Smirnova & Max Neg Differnc $=0,00$ & $<0,001$ \\
\hline & & & Max Pos Differnc $=1,000000$ & \\
\hline & & Walda-Wolfowica & $Z=-7,55204$ & 0,000000 \\
\hline & & & $Z$ adjstd $=7,421834$ & 0,000000 \\
\hline & 1 and 5 & Manna-Whitney & $\mathrm{U}=0,00$ & 0,000000 \\
\hline & & & $Z=6,645599$ & \\
\hline & & Kolmogorov-Smirnova & Max Neg Differnc $=0,00$ & $<0,001$ \\
\hline & & & Max Pos Differnc $=1,000000$ & \\
\hline & & Walda-Wolfowica & $Z=-7,55204$ & 0,000000 \\
\hline & & & $Z$ adjstd $=7,421834$ & 0,000000 \\
\hline & 1 and 2 & Manna-Whitney & $\mathrm{U}=0,00$ & 0,000000 \\
\hline & & & $\mathrm{Z}=6,645599$ & \\
\hline & & Kolmogorov-Smirnova & Max Neg Differnc $=0,00$ & $<0,001$ \\
\hline & & & Max Pos Differnc $=1,000000$ & \\
\hline & & Walda-Wolfowica & $Z=-7,55204$ & 0,000000 \\
\hline & & & $\mathrm{Z}$ adjstd $=7,421834$ & 0,000000 \\
\hline & 1 and 3 & Manna-Whitney & $\mathrm{U}=0,00$ & 0,000000 \\
\hline & & & $Z=6,645599$ & \\
\hline & & Kolmogorov-Smirnova & Max Neg Differnc $=0,00$ & $<0,001$ \\
\hline & & & Max Pos Differnc $=1,000000$ & \\
\hline & & Walda-Wolfowica & $Z=-7,55204$ & 0,000000 \\
\hline ] & & & $\mathrm{Z}$ adjstd $=7,421834$ & 0,000000 \\
\hline in & 1 and 4 & Manna-Whitney & $\mathrm{U}=0,00$ & 0,000000 \\
\hline & & & $Z=6,645599$ & \\
\hline & & Kolmogorov-Smirnova & Max Neg Differnc $=0,00$ & $<0,001$ \\
\hline & & & Max Pos Differnc $=1,000000$ & \\
\hline & & Walda-Wolfowica & $\mathrm{Z}=-7,55204$ & 0,000000 \\
\hline & & & $\mathrm{Z}$ adjstd $=7,421834$ & 0,000000 \\
\hline & 1 and 5 & Manna-Whitney & $\mathrm{U}=0,00$ & 0,000000 \\
\hline & & & $\mathrm{Z}=6,645599$ & \\
\hline & & Kolmogorov-Smirnova & Max Neg Differnc $=0,00$ & $<0,001$ \\
\hline & & & Max Pos Differnc $=1,000000$ & \\
\hline & & Walda-Wolfowica & $\mathrm{Z}=-7,55204$ & 0,000000 \\
\hline & & & $\mathrm{Z}$ adjstd $=7,421834$ & 0,000000 \\
\hline & 1 and 2 & Manna-Whitney & $\mathrm{U}=0,00$ & 0,000000 \\
\hline & & & $Z=6,645599$ & \\
\hline & & Kolmogorov-Smirnova & Max Neg Differnc $=0,0000$ & $<0,001$ \\
\hline & & & Max Pos Differnc $=1,000000$ & \\
\hline & & Walda-Wolfowica & $\mathrm{Z}=-7,55204$ & 0,000000 \\
\hline & & & $Z$ adjstd $=7,421834$ & 0,000000 \\
\hline & 1 and 3 & Manna-Whitney & $\mathrm{U}=0,00$ & 0,000000 \\
\hline & & & $Z=6,645599$ & \\
\hline & & Kolmogorov-Smirnova & Max Neg Differnc $=0,00$ & $<0,001$ \\
\hline & & & Max Pos Differnc $=1,000000$ & \\
\hline & & Walda-Wolfowica & $Z=-7,55204$ & 0,000000 \\
\hline 胥 & & & $\mathrm{Z}$ adjstd $=7,421834$ & 0,000000 \\
\hline$\sqrt{n}$ & 1 and 4 & Manna-Whitney & $\mathrm{U}=0,00$ & 0,000000 \\
\hline & & & $\mathrm{Z}=6,645599$ & \\
\hline & & Kolmogorov-Smirnova & Max Neg Differnc $=0,00$ & $<0,001$ \\
\hline & & & Max Pos Differnc $=1,000000$ & \\
\hline & & Walda-Wolfowica & $\mathrm{Z}=-7,55204$ & 0,000000 \\
\hline & & & $\mathrm{Z}$ adjstd $=7,421834$ & 0,000000 \\
\hline & 1 and 5 & Manna-Whitney & $\mathrm{U}=0,00$ & 0,000000 \\
\hline & & & $\mathrm{Z}=6,645599$ & \\
\hline & & Kolmogorov-Smirnova & Max Neg Differnc $=0,00$ & $<0,001$ \\
\hline & & & Max Pos Differnc $=1,000000$ & \\
\hline & & Walda-Wolfowica & $\mathrm{Z}=-7,55204$ & 0,000000 \\
\hline & & & $\mathrm{Z}$ adjstd $=7,421834$ & 0,000000 \\
\hline & 1 and 2 & Manna-Whitney & $\mathrm{U}=0,00$ & 0,000000 \\
\hline & & & $\mathrm{Z}=6,645599$ & \\
\hline$\overbrace{}^{2}$ & & Kolmogorov-Smirnova & Max Neg Differnc $=0,00$ & $<0,001$ \\
\hline$\Xi$ & & & Max Pos Differnc $=1,000000$ & \\
\hline & & Walda-Wolfowica & $\mathrm{Z}=-7,55204$ & 0,000000 \\
\hline
\end{tabular}




\begin{tabular}{|c|c|c|c|}
\hline & & $\mathrm{Z}$ adjstd $=7,421834$ & 0,000000 \\
\hline \multirow[t]{6}{*}{1 and 3} & \multirow[t]{2}{*}{ Manna-Whitney } & $\mathrm{U}=0,00$ & \multirow[t]{2}{*}{0,000000} \\
\hline & & $Z=6,645599$ & \\
\hline & \multirow[t]{2}{*}{ Kolmogorov-Smirnova } & Max Neg Differnc $=0,00$ & \multirow[t]{2}{*}{$<0,001$} \\
\hline & & Max Pos Differnc $=1,000000$ & \\
\hline & \multirow[t]{2}{*}{ Walda-Wolfowica } & $Z=-7,55204$ & 0,000000 \\
\hline & & $Z$ adjstd $=7,421834$ & 0,000000 \\
\hline \multirow{6}{*}{1 and 4} & \multirow[t]{2}{*}{ Manna-Whitney } & $\mathrm{U}=35,50000$ & \multirow[t]{2}{*}{0,000000} \\
\hline & & $Z=6,120752$ & \\
\hline & \multirow[t]{2}{*}{ Kolmogorov-Smirnova } & Max Neg Differnc $=0,00$ & \multirow[t]{2}{*}{$<0,001$} \\
\hline & & Max Pos Differnc $=0,800000$ & \\
\hline & \multirow[t]{2}{*}{ Walda-Wolfowica } & $\mathrm{Z}=-5,46872$ & 0,000000 \\
\hline & & $Z$ adjstd $=5,338512$ & 0,000000 \\
\hline \multirow{6}{*}{1 and 5} & \multirow[t]{2}{*}{ Manna-Whitney } & $\mathrm{U}=0,00$ & \multirow[t]{2}{*}{0,000000} \\
\hline & & $Z=6,645599$ & \\
\hline & \multirow[t]{2}{*}{ Kolmogorov-Smirnova } & Max Neg Differnc $=0,00$ & \multirow[t]{2}{*}{$<0,001$} \\
\hline & & Max Pos Differnc $=1,000000$ & \\
\hline & \multirow[t]{2}{*}{ Walda-Wolfowica } & $Z=-7,55204$ & 0,000000 \\
\hline & & $\mathrm{Z}$ adjstd $=7,421834$ & 0,000000 \\
\hline
\end{tabular}

According to the data presented in the table, it is obvious that SOD activity in rat skeletal muscle tissue of all experimental groups starting from 1 day of the experiment and up to the end of the experiment differs from the enzyme activity in intact animals.

\section{Conclusions}

In case of mechanical damage to the eye, according to numerous studies, an inflammatory process occurs due to a number of protective mechanisms, one of which is a hematoophthalmic barrier. Its damage is accompanied by autoimmune reactions and development of stress immunosuppression. In part, its severity is due to the stress of losing an information important organ. As a rule, the early period $(24-48 \mathrm{~h})$ is accompanied by immunodepression, anxiety and adaptation syndrome. All these factors, along with mechanical trauma, induce and stimulate oxidative stress, which aggravates the severity of the pathological process. In this case, oxidative stress becomes one of the most important factors complicating the process of eye therapy [20]. Superoxide dismutase, as one of the enzymes of the antioxidant system, is actively involved in the fight against the resulting particles and its activity in tissues is reduced. In this case, the use of quercetin bioflavonoid, which has proven efficacy in the treatment of chronic eye diseases, due to its ability to be a hydrogen donor, a single oxygen extinguisher, a metal ion chelator, an activator of antioxidant enzymes, is quite justified [21]. In general, according to the results of the experiment, it was found that in addition to the standard therapy of mechanical eye injury injection of quercetin is the most effective way to stop oxidative stress and normalize the activity of SOD in the skeletal muscle tissue.

Conclusion: ODS activity in rat skeletal muscle tissue under oxidative stress caused by mechanical action on the hemato-ophthalmic barrier is most effectively stabilized in standard therapy of mechanical eye injury with the addition of quercetin in the form of injections.

\section{References}

1. P. Baranowski, et al., The Scientifi c World Journal (2014) http://dx.doi.org/10.1155/2014/861904 (Last accessed 01.08.2020)

2. O. N. Pavlova, S. A. Simakova, Medico-physiological problems of human ecology: materials of the IV All-Russian Conference with international participation (26-30 September 2011), 244-246 (2011) 
3. N. A. Datson, et al., Endocrinology, 154, 3261-3272 (2013)

4. C. Barrios, Eur. J. Appl. Physiol., 111(7), 1341-1350 (2011)

5. A.G. Hindle, et al., Comp. Biochem. Physiol. B. Biochem. Mol. Biol., 4(155), 427-234 (2010)

6. M. Mittal, et al., Antioxid. Redox Signal., 20, 1126-1167 (2014)

7. F. Changjian, Coord Chem Rev., 256(3-4), 393-411 (2012) doi: 10.1016/j.ccr.2011.10.011

8. J. Dong, et al., Int. J. Biol. Sci., 7(6), 881-891 (2011)

9. A. Rao, et al., PLoS One. 5(6), 18 (2010) doi: 10.1371/journal.pone.0011209

10. C. Barrios, Eur. J. Appl. Physiol., 111(7), 1341-1350 (2011)

11. P. D. Ray, et al., Cell Signal., 24(5), 981-990 (2012)

12. I. Heinonen, et al., Am. J. Physiol. Regul. Integr. Comp. Physiol., 302(3), 385-390 (2012)

13. I. Heinonen, et al., Nutr Metab (Lond), 18-1-0(1), 43 (2013) doi: 10.1186/1743-707510-43.

14. M. C. Fogarty, et al., Front. Physiol., 52(1), 35-42 (2011)

15. Z. Radak, et al., Antioxid. Redox Signal., 18-10, 1208-1246 (2013) doi: 10. 1089/ars. 2011. 4498

16. C. Isaksson, et al., BioScience., 61-3, 194-202 (2011)

17. S. K. Powers, et al., J. Physiol., 589(9), 2129-2138 (2011)

18. H. Sies, et al., Annu. Rev. Biochem., 86, 715-748 (2017)

19. F. Kyota, et al., Medicine and cellular longevity., 1, 9 (2012)

20. N. Chaudhari, et al., Frontiers in Cellular Neuroscience, 8, 165-172 (2014)

21. F. Kyota, et al., Medicine and cellular longevity., 1, 9 (2012) 